\title{
Report of the IMA Commission on the Physics of Minerals 2011-2014
}

\author{
Eiji Ohtani
}

Published online: 3 June 2014

(C) Springer-Verlag Berlin Heidelberg 2014

The Commission on the Physics of Minerals (CPM) was established within the International Mineralogical Association (IMA) for promotion of the application of modern solid-state physics to minerals at low and high temperatures as well as at high pressures and dynamics of the earth and planetary interiors through the organization of workshops, conferences and publications. We created four sub-commissions during the 2010 business meeting of the CPM which were approved by Council at the 2010 IMA General Meeting, Budapest. The four sub-commissions are: (1) Earth deep interior, (2) glass and melt studies and their applications to geosciences and industry, (3) spectroscopy, diffraction, and new instrumentations in mineral physics, (4) theoretical and computing mineral physics. Members of the sub-commissions have been active during the past 4 years in organizing scientific sessions on topics relevant to the CPM not only at the quadrennial IMA General Meeting but also at many national and international meetings.

The CPM and its sub-commissions are actively involved in the upcoming 21st IMA General Meeting taking place in South Africa in September, 2014. Four sessions are being convened by the CPM: "Mineralogy in the Deep Earth" (sub-commission for Earth deep interior); "Magmas and melts under extreme conditions" (sub-commission for glass and melt studies and their applications to geosciences and industry); "Theoretical and computational mineral physics for Deep Earth" and "Mineralogy of the Outer Solar System" (both convened by the sub-commission for theoretical and computing mineral physics).

E. Ohtani $(\bowtie)$

Department of Earth Science, Graduate School of Science,

Tohoku University, Sendai, Miyagi-ken 980-8578, Japan

e-mail: ohtani@m.tohoku.ac.jp
The members of the CPM and its four sub-commissions have been active in organizing and convening sessions in all of the Goldschmidt conferences held during the period 20112014. For example, during the Goldschmidt conference held in Florence, Italy, in August 2013, they co-organized the following themes: "The cutting edge in mineralogy and mineral physics", "Deep Earth", and "Melts, glasses, magmas: from properties to processes". Under these themes, the following sessions were co-convened by CPM members: "High-pressure mineral physics: A key to study Earth's dynamics", "Deep transport of subducted material: escaping the meat grinder", and "Latest news on the structure of melts and glasses".

In addition to the above activities, CPM members convened sessions in many international and national meetings of societies and other organizations and delivered keynote and invited talks (e.g. AGU, EGU, JPGU, AOGS, COMPRES, WPGM 2012, XXV IUGG General Assembly 2011, and SMEC meetings 2011 and 2013). Many CPM members play key roles in organizations focusing on mineral physics and related fields, including as section president and committee members of sections and focus groups of AGU, president of COMPRES, section president of JPGU, and committee members of national societies involving mineralogy and mineral physics. Through all of these activities, the CPM and its members have contributed significantly to the promotion of mineral physics and geodynamics at both national and international levels.

Eiji Ohtani, Chair of the IMA Commission on the Physics of Minerals. 